\section{Health Secretary pressed to set out tooth extraction action plan}

The British Dental Association (BDA) has joined with sector leaders and learning disability charity Mencap to press Health Secretary Matt Hancock to set out an action plan to ease the backlog on tooth extractions in hospitals, warning many young and vulnerable patients across England are now expected to see waiting times of up to a year lengthen significantly.

Extractions are the responsibility of community dental services and hospital dental services. Frontline intelligence gathered by the BDA across the English regions suggests many

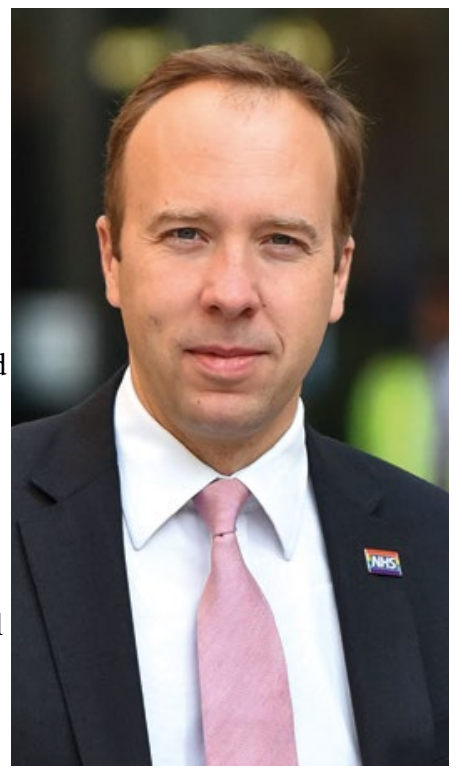
services have yet to resume treatment since the start of lockdown, and where they have the capacity has often halved to meet social distancing and additional infection control procedures.

Tooth decay has been immovable as the number one reason for hospital admissions among young children, with recent analysis by the Local Government Association indicating 180 procedures took place every working day in England in 2018/19 on patients aged under 18.

Extractions formed part of the many elective procedures that were postponed among 50,000 children from March to May. High demand and underinvestment had seen waiting times hit over a year prior to the pandemic, a figure which is now expected to surge. Official targets for delivering treatment vary by area from four to 18 weeks, owing to different approaches to commissioning services.

In an open letter to the Health Secretary the group has called for an urgent action plan, and to publish an internal Public Health England review into the true scale of extractions under general anaesthetic, which is thought to be significantly understated in official statistics.

Charlotte Waite, Chair of the BDA's England Community Dental Services Committee said: 'The government has a responsibility to act of for patients, many of whom were already facing a year of toothache 突 and the impact this has on their general wellbeing.

'We need a plan, and full disclosure on the true scale of a problem $\circlearrowleft$ that is already a national scandal.'

\section{Death announcement}

We regret to announce the recent death of Francis William O’Daly.

\section{Eddie Crouch is new BDA Chair}

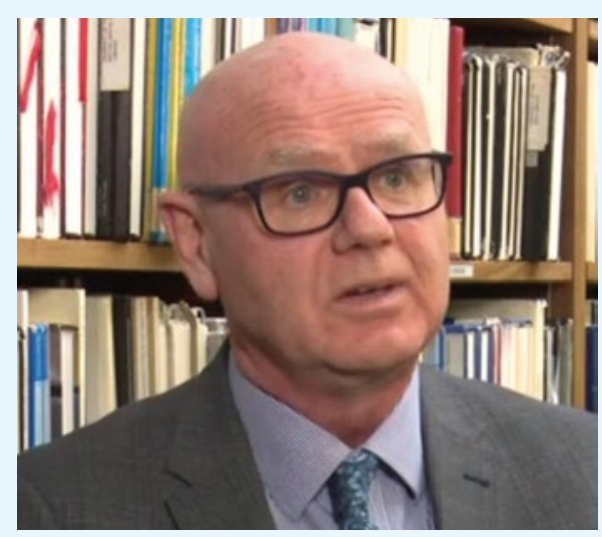

Eddie Crouch has been elected as the new chair of the British Dental Association's (BDA's) Principal Executive Committee (PEC).

Vice chair of the PEC since 2014, Eddie served as secretary of Birmingham Local Dental Committee for over ten years and is now its chair.

Eddie (pictured) qualified in 1984 from King's and currently provides orthodontic care for patients in South Birmingham. He previously chaired the Annual Conference of LDCs, held the post of president of the Central Counties Branch and served on the General Dental Practice Committee for over a decade. Until recently he chaired the West Midlands Association of LDCs.

In 2007 he successfully challenged a termination clause in personal dental services (PDS) agreements in the High Court.

Peter Crooks (Northern Ireland) has been elected as the new deputy chair, with Shareena Ilyas (Greater London) to serve as chair of the Education, Ethics and the Dental Team Working Group.

Eddie said: 'I take office at a time when dental services that millions depend on are under threat, and as we struggle to recover and restore care. There is now, however, a real opportunity to break from failed systems that were already creaking before COVID-19.

'The BDA rose to the challenge at lockdown, refocusing all its efforts in the face of a unique threat. That work is far from over, but it illustrates how we must move forward: mobilising to meet challenges head on.

'We have seen what the world looks like without dental care. It's our responsibility to build on this, to shine a light on the vital services our members provide, and the barriers they face. Colleagues facing real financial risks need ongoing help. For patients it's essential that services are supported and improved.

'My responsibility is to listen and to lead. I intend to work with staff and representatives from across the profession in all four nations to set a direction that improves on the benefits our members enjoy, secures the future of the organisation and builds its influence. And now, more than ever, it means providing an Association that colleagues want to be a part of.' 